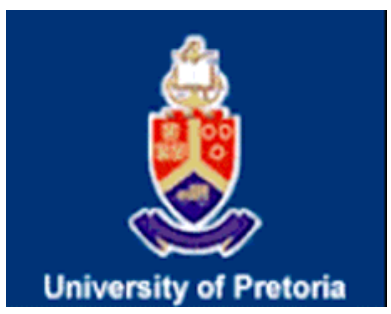

University of Pretoria

Department of Economics Working Paper Series

\title{
Testing for PPP Using SADC Real Exchange Rates
}

Thabo Mokoena

South African Reserve Bank

Rangan Gupta

University of Pretoria

Renee van Eyden

University of Pretoria

Working Paper: 2008-22

June 2008

Department of Economics

University of Pretoria

0002, Pretoria

South Africa

Tel: +27 124202413

Fax: +27 123625207 


\title{
TESTING FOR PPP USING SADC REAL EXCHANGE RATES
}

\author{
Thabo M. Mokoena*, Rangan Gupta** and Reneé van Eyden ${ }^{* * *}$
}

\begin{abstract}
This paper attempts to provide evidence indicating that the Purchasing Power Parity (PPP) puzzle is becoming less of a puzzle. It present the results of Augmented DickeyFuller (ADF) test, nonlinear tests of nonstationarity, and Bayesian unit root tests, applied to ten SADC countries. The Bayesian tests were found to be biased in favour of a trend stationary model in all cases. It is argued that nonlinear approaches to exchange rate adjustments are likely to provide a firmer basis for inference and stronger support for the PPP in the long-term. This is more so at 1 per cent and 5 per cent levels of significance.
\end{abstract}

JEL Codes: C11, C22, F31.

Keywords: Purchasing Power Parity, Nonlinear Nonstationarity Tests, Bayesian Unit Root Test.

\section{INTRODUCTION}

International macroeconomics continues to have a menu of puzzles that require new theoretical and empirical explanations. Obstfeld and Rogoff (2000) have identified 6 major puzzles of international macroeconomics. Four of these relate to exchange rate economics and they are the purchasing power parity puzzle (PPP), the exchange rate disconnect puzzle, the exchange rate determination puzzle and the forward premium puzzle.

The broad motivation of the paper is derived from the basic recognition that there continues to be a need to find solutions to major exchange rate puzzles mentioned above. In the context of this paper, however, the puzzle of interest is the purchasing power parity (PPP) puzzle $^{1}$ in the Southern African Development Community (SADC). ${ }^{2}$

\footnotetext{
${ }_{\star \star}^{*}$ Economist, South African Reserve Bank. Contact Details: Thabo.Mokoena@resbank.co.za.

** Corresponding Author. Associate Professor, Department of Economics, University of Pretoria. Contact Details: Department of Economics, University of Pretoria, Pretoria, 0002, South Africa, Phone: + 2712420 3460, Fax: + +27 12362 5207, Email: Rangan.Gupta@up.ac.za.

Associate Professor, Department of Economics, University of Pretoria. Contact Details: Department of Economics, University of Pretoria, Pretoria, 0002, South Africa, Phone: + 2712420 3456, Fax: + +27 12362 5207, Email: renee.vaneyden@up.ac.za.

1 See Mokoena (2007) and Mokoena et al. (2008a, 2008b) for theoretical and empirical analyses of the exchange rate disconnect puzzle and the exchange rate determination puzzle.

2 Currently the SADC is constituted by Angola, Botswana, the Democratic Republic of Congo (DRC), Lesotho, Malawi, Madagascar, Mauritius, Mozambique, Namibia, South Africa, Swaziland, Tanzania, Zambia, and Zimbabwe. Owing to a lack of reliable data, four countries have been excluded in the analysis: the DRC, Lesotho, Namibia, and Zimbabwe.
} 
Specifically, this paper analyses the mean-reversion version ${ }^{3}$ of the PPP in SADC countries by presenting hypothesis testing in respect of joint tests of nonlinearity and stationarity associated with the seminal contribution by Kapetanios, Shin and Snell (2003), henceforth denoted KSS. It also presents the results of the Augmented DickeyFuller (1981) (ADF) tests, as is generally used for testing for PPP, and, the recently developed, Bayesian unit root tests at conventional levels.

As far as the specific motivation for this paper is concerned, it emanates from the recognition of the recent literature for the need, one hand, to assess nonlinearities in the adjustment dynamics of real exchange rates, on the other hand, to look for Bayesian alternatives to the classical approach of the ADF test to test for staionarity. The main reason for this paradigm shift is that, due to lower power in small sample sizes, the standard Dickey-Fuller-type tests do not provide a solid foundation for an inference that reduces the probability of committing a Type 2 error. This has been the case even when stronger versions of Dickey-Fuller tests - such as the one suggested by Elliot, Rotenberg and Stock (1996) - were used.

The focus on nonlinearities has been reinforced by Sarno, Taylor and Peel (2001) who provide strong evidence that four major real bilateral dollar exchange rates were characterized by nonlinear mean-reversion. One influential study that has also corroborated nonlinear mean-reversion is by Michael, Nobay and Peel (1997). In the nonlinear models, an equilibrium level of the real exchange rate in the regime in which the log-level of the real exchange rate is close to a random walk becomes increasingly mean reverting as the absolute size of the deviation from equilibrium increases. This is consistent with the recent theoretical literature on the nature of real exchange rate dynamics in the presence of transaction costs (See Sercu, Uppal and van Hulle (1995)).

The pressing need to use Bayesian methods of unit root testing originates from the work of Sims (1988), DeJong and Whiteman (1991), Sims and Uhlig (1991) and Koop (1992). These economists point out that the ADF tests have low power against other plausible alternatives, mainly the trend-stationary assumption. However, the Bayesian approach, assigns similar posterior probabilities to both the unit root and the trend-stationary hypotheses, and, hence, should provide a more reasonable description of sample information than the classical approach. Further, as Sims (1988) points out, another problem with the classical unit-root tests is the discontinuity of the classical asymptotic theory when there is a unit root, but given that the Bayesian methodology is based on the likelihood function, it does not suffer from the same discontinuity problem. Finally, Koop (1994) indicates that, in the classical approach, small sample critical values, generally used in studies involving unit root testing, could differ from the asymptotic critical values quite substantially as well as frequently. The Bayesian methodology, however, being conditional on the observed sample, tends to provide exact small sample results.

\footnotetext{
3 See Section 2 for further details. For a detailed discussion of the half-life version of the PPP, and their applications to SADC countries, refer to Mokoena (2007) and Mokoena et al.. (2008a). Also see Mokoena et al. (2008c) for an appraisal of the possibility that SADC country real exchange rates can be treated as long memory processes.
} 
In such a backdrop, this paper realises the importance of going beyond the standard tests of stationarity, such as the ADF test, and delving into not only non-linear but also Bayesian unit root tests. To the best of our knowledge, this is the first attempt to solving the PPP for SADC countries, with the exception of South Africa, using recent methodological advances in testing for stationarity. Recently, Mokoena (2007) presented the results of nonlinearity and stationarity tests in respect of the real exchange rates of the South African rand. The author found that the rand real exchange rate behaviour tends to be nonlinear and stationary in a majority of cases in the sample. This, in turn, suggested that, for the majority of the currencies in the sample, the real exchange rates of the rand were mean-reverting, implying that the purchasing power parity relation tended hold in a nonlinear manner for South Africa. This study, thus, extends the work of Mokoena (2007) by considering a larger number of countries. ${ }^{4}$

It should be pointed out at the very beginning that this paper does not focus on the topics of optimal currency areas in the context of SADC. Nor does it concern itself with issues of macroeconomic convergence, which would typically include budget deficit ratios, inflation rates, public debt ratios, external balance, exchange rates and interest rates. In the context of PPP analysis, this study only seeks to identify dollar-based meanreversion in the SADC.

An analysis of SADC exchange rates within and beyond the PPP hypothesis generally faces several conceptual hurdles and possible pitfalls. First, outside South Africa, capital markets are less advanced and less liquid, and cross-border capital flows tend to be limited, making the real interest rate differentials as fundamentals less likely to play a significant role in equilibrium. Second, low-income SADC countries tend to be heavily indebted, with debt service and/or official grants constituting a significant fraction of gross domestic product (GDP), a situation that likely influences the real exchange rate determination more than the market forces. Also, low-income SADC countries tend to be commodity exporters with only a small share of manufacturing exports. Thus, the preponderance of world prices of certain commodities is likely to affect both the external current account of the balance of payments and the equilibrium real exchange rate. Additional pitfalls in respect of PPP analysis have been discussed in detail by Taylor (2000). That said, it is not clear how these institutional factors affect the statistical properties of the real exchange rate time series. The remainder of the paper is organised as follows: Section 2 introduces the PPP puzzle formally, and discusses the recent theoretical and empirical improvements that attempt to resolve the puzzle. Section 3 presents the empirical approaches used to resolve this puzzle in the context of SADC, while, Section 4 presents the data and the empirical evidence. Finally, Section 5 concludes.

\footnotetext{
4 Since we use the same data set as that in Mokoena (2007) for South Africa, we obtain the exact results as reported in Mokoena (2007). See Section 4 for further details.
} 


\section{THE PPP PUZZLE: MEAN-REVERSION}

An ordinary definition of absolute purchasing power parity (PPP) is that the latter represents the exchange rate between two currencies multiplied by the relative national price levels. The relative form of this hypothesis is that PPP exists when the rate of depreciation of, say, the home currency relative to the foreign currency matches the difference in aggregate price inflation between the two countries in point (Sarno and Taylor, 2002).

The PPP hypothesis implies that the real exchange rate should be constant such that any deviations from equilibrium should be transitory. Yet most studies have found that real exchange rates exhibit a large degree of volatility and that their deviations from equilibrium are highly persistent.

Formally, the relative form of PPP admits the following logarithmic representation:

$y_{t} \equiv s_{t}-p_{t}+p_{t}^{*}$,

where $y_{t}$ is a measure of deviation from PPP, $s_{t}$ is the nominal exchange rate, $p_{t}$ denotes the domestic price level, and $p^{*}{ }_{t}$ represents the foreign price level.

From a historical perspective, real exchange rates play an important role in establishing parities and in estimating national income levels for comparative purposes (Sarno, Taylor and Peel, 2001). In addition, there are policy implications in determining the degree of persistence of real exchange rates. For instance, if the real exchange rate is highly persistent or near unit root, its adjustment is likely to impact upon the real side of the economy -- productivity and tastes. By contrast, a low level of persistence is associated with shocks on the aggregate demand.

Today it is still a matter of debate whether the PPP relation holds in both the long-run and the short run. At the level of theoretical discussion, the violation of PPP in the short run can be explained through the theory of exchange rate overshooting, in which the PPP deviations are expected to occur as explained by Dornbusch (1976). However, in the long-run, for the PPP to hold, it must admit mean reversion. So, empirically speaking, an econometrician would like to see the real exchange rate remain stationary, while the alternative hypothesis would suggest that the exchange rate was a unit root process or a random walk. Formally, a manifestation of mean-reversion implies that, under the assumption of linearity, the following relation from (2.1) should hold:

$y_{t}=\alpha+\rho y_{t-1}+\varepsilon_{t}, \quad 0<\rho<1$.

When $\rho=1$, equation (2) becomes a unit root process. It means the process does not allow the system to come back to equilibrium. An implication of a real exchange rate with a unit root is that, among other things, it limits the usefulness of the PPP exchange rates used for policy purposes. 
On balance, evidence on the long-term PPP, while in some cases is supportive of the relation, is influenced by the techniques used by researchers. For instance, the current literature focuses on linear and nonlinear tests of nonstationarity, linear and nonlinear cointegration tests, and panel data studies, to name a few.

As far as panel data techniques are concerned, Abuaf and Jorion (1990) analysed a system of $10 A R(1)$ regressions for real dollar exchange rates. They tested the null hypothesis that the real exchange rates were jointly nonstationary for all the 10 series over the sample period 1973 to 1987 . Their results indicated a positive support for the stationarity of real exchange rates at conventional levels of significance, suggesting that there was evidence in favour of PPP. Other panel data studies include Levin and Lin (1992), who tested the null hypothesis that each individual series was an $I(1)$ against the alternative that all the series as a panel were stationary. Frankel and Rose (1995), Wu (1996) and Oh (1995) have relied on Levin and Lin (1992) panel unit root test to establish mean reversion in real exchange rates.

There are other studies utilising univariate approaches and multivariate methods and these are surveyed extensively by Sarno and Taylor (2002).

Moreover, as shown in Bailie and Kapetanios (2005), exchange rates seem to harbour neglected nonlinearities of unknown form. A detailed discussion concerning nonlinear mean-reversion is found in Sarno, Taylor and Peel (2001). In the latter study the authors provide evidence of nonlinear mean reversion in a number of major real exchange rates during the post-Bretton Woods period. The study undertakes multivariate unit root tests with high power to reject the null hypothesis of unit root behaviour in exchange rates.

Moreover, there is a growing realisation that, due to their lack of power, the standard tests of nonstationarity in the univariate context are unable to provide a strong foundation for inference that reduces the high probability of committing type 2 errors in the PPP studies.

More formally, traditional unit root tests involve testing the null hypothesis of $z_{t}=z_{t-1}+\varepsilon_{t}$ against equation (2). This leads to the application of an augmented DickeyFuller test statistic:

$\Delta z_{t}=\phi_{0}+\phi_{1} t+\phi_{2} z_{t-1}+\sum_{i=1}^{n-1} \beta_{i} \Delta z_{t-i}+v_{t}$.

The poor power performance of the standard unit root tests has been reported by many studies, including Balke and Fomby (1997), Pipenger and Goering (1993), Diebold and Rudebusch (1991), and Sarno, Taylor and Peel (2001).

Due to the problems mentioned above, the resolution of the PPP will require fairly robust tests of nonstationarity and nonlinearity. The details of the empirical methodologies are presented below in Section 3. 


\section{THE TESTING FRAMEWORKS}

(a) The ESTAR Testing Framework

In the context of nonlinearities, the testing framework is the smooth transition autoregressive modelling. In particular, we focus on the exponential version of the model, which is often used when the economic agents can have arbitrage opportunities by facing some deviation from the long-run equilibrium. In such a case, the unit root regime becomes an inner regime, and the mean-reverting regime becomes the outer regime.

In this setting, let $y_{t}$ be real exchange rate time series observed at $t=1-p, 1-(p-1), \ldots-1,0,1 \ldots T-1, T$. Let $\Omega_{t-1}=\left\{y_{t-1}, y_{t-2}, \ldots, y_{1-(p-1)}, y_{1-p}\right\}$. When time series is stationary we can assume that $E\left[\varepsilon_{t}^{2} \mid \Omega_{t-1}\right]=\sigma^{2}$.

Consider the following representation of the exponential STAR model:

$y_{t}=a_{1} y_{t-1}+a_{2} y_{t-1} F\left(\gamma y_{t-d}\right)+\varepsilon_{t}$

where $F\left(\gamma y_{t-d}\right) \equiv 1-\exp \left(-\gamma y_{t-d}^{2}\right)$.

In equation (4), $y_{t-d}$ is a transition variable, making this ESTAR model a self-exciting one. The delay parameter $d$ is an integer, which can be fixed or be determined endogenously by means of a supremum LM test in the spirit of Norman (2006). In equation (5), $F\left(y_{t-d}\right)$ represents the exponential transition function. We note that the extreme values of the transition function are 0 and 1 . So, for $F 0>0$ and $F 0<1$, the model exhibits a smooth regime-switching behaviour. The parameter $\gamma$ determines the smoothness of the transition from one regime to another. We note that as $y_{t} \rightarrow \pm \infty$, then the transition function $F(\rightarrow 0$. In addition, as $\gamma \rightarrow 0$ or $\gamma \rightarrow \infty$, then $F\left(s_{t}, \gamma, c\right)=0$.

The null hypothesis of a unit root or no long-run equilibrium implies:

$H_{0}: a_{1}=1$

This leads to an AR(1) model:

$y_{t}=a_{1} y_{t-1}+\varepsilon_{t}$

where $a_{1}=1$.

Under the alternative hypothesis, the model becomes

$y_{t}=\left\{a_{1}+a_{2} y_{t-1}\left[1-\exp \left(-\gamma y_{t-d}^{2}\right)\right]\right\} y_{t-1}+\varepsilon_{t}$

and

$H_{1}: \gamma>0$.

The null hypothesis cannot be tested directly due to the fact that $a_{2}$ and $\gamma$ are not identified under the null hypothesis. This is called the Davies (1987) problem. According 
to KSS, testing for nonlinearity in the context of possible nonstationarity requires an auxiliary regression of the form:

$$
\Delta y_{t}=\delta y^{3}{ }_{t-1}+\text { error }
$$

In the presence of serial correlation, the auxiliary regression takes the form:

$$
\Delta y_{t}=\sum_{j=1}^{p} \varphi_{j} \Delta y_{t-j}+\delta y^{3}{ }_{t-1}+\text { error }
$$

KSS developed a nonlinear ADF t-test, denoted NLADF - $t$, of the form:

$$
N L A D F-t=\frac{\hat{\delta}}{\text { s.e. }(\hat{\delta})},
$$

where $\hat{\delta}$ is the estimator of $\delta$ in (8) or (9) and s.e. is the standard error of regression. The $N L A D F-t$ statistic is accompanied by a nuisance-parameter-free asymptotic distribution of the following form:

$$
N L A D F \Rightarrow \frac{\left\{1 / 4 B(1)^{4}-3 / 2 \int_{0}^{1} B(r)^{2} d r\right\}}{\sqrt{\int B(r)^{6} d r}}
$$

where $B(r)$ is the standard Brownian motion defined on $r \in[0,1]$.

In essence, the unit root test is for testing the null hypothesis of non-mean reverting time series against the alternative hypothesis of a globally ergodic nonlinear process.

\section{(b) Bayesian Unit Root Testing}

Over and above the ESTAR testing, for comparative purposes we employ Bayesian unit root tests in conjunction with the ADF tests. Bayesian unit root testing was introduced by Zellner and Siow (1980) but was popularised by Koop (1992) and Ahking (1997, 2004), among others. Under the null hypothesis, a times series is an autoregressive model of order $\mathrm{p}$ with a linear time trend. In short, hypothesis testing takes the following form:

$$
\begin{aligned}
& H_{1}: y_{t}=\beta_{0}+\sum_{i=1}^{p} \beta_{i} y_{t-i}+\beta_{p+1} t+\varepsilon_{1 t} \\
& H_{2}: y_{t}=\beta_{0}+\sum_{i=1}^{p} \beta_{i} y_{t-i}+\varepsilon_{2 t}, \beta_{p+1}=0
\end{aligned}
$$




$$
\begin{aligned}
& \left.H_{3}: \Delta y_{t}=\beta_{0}+\left(\sum_{i=2}^{p} \beta_{i}\right) \Delta y_{t-i}-\left(\sum_{i=3}^{p} \beta_{p+i}\right) \Delta y_{t-i}-\beta_{p} \Delta y_{t-(p-1}\right)-\ldots-\beta_{p} \Delta y_{p-1}+\varepsilon_{3 t} \\
& \sum_{i=1}^{p} \beta_{i}=1, \beta_{p+1}=0, \\
& H_{4}: \Delta y_{t}=\beta_{0}+\left(\sum_{i=2}^{p} \beta_{i}\right) \Delta y_{t-i}-\left(\sum_{i=3}^{p} \beta_{p+i}\right) \Delta y_{t-2}-\beta_{p} \Delta y_{t-(p-1)}-\ldots-\beta_{p} \Delta y_{p-1}+\varepsilon_{3 t}, \\
& \sum_{i=1}^{p} \beta_{i}=1,
\end{aligned}
$$

where $t$ denotes a linear deterministic time trend; and $\varepsilon_{j t}, j=2,3,4$ represents a serially uncorrelated error process with zero mean and constant variance. $H_{1}$ represents the null model, hypothesising a trend-stationary auto-regressive process of order $p$. The first alternative against the null, hypothesises a stationary $A R(p)$ process, while the second alternative hypothesises an $A R(p)$ process with a unit root. It is to be noted that $H_{2}$ and $\mathrm{H}_{3}$ are special cases of the null hypothesis, with linear restrictions imposed on the null model. The trend-stationary hypothesis is included because it is the leading alternative to unit-root non-stationarity in macroeconomic time series. According to Ahking (2004), the stationary alternative is included to appraise the extent to which the Bayesian test can distinguish between nonstationary series and a stationary one with a high degree of persistence, as is frequently encountered in time series econometrics.

We compare the four hypotheses, based on both prior and sample information, by calculating the posterior odds ratios:

$$
K_{1 j}=\frac{\left[P\left(H_{1}\right) P\left(H_{j}\right)\right] P\left(H_{1} \mid \tilde{y}\right)}{P\left(H_{j} \mid \tilde{y}\right)}
$$

where $\tilde{y}$ is the sample data; $P\left(H_{1}\right) / P\left(H_{j}\right)$ denotes the prior odds ratio, and $P\left(H_{i} \mid \tilde{y}\right)$ is the posterior probability that $\mathrm{H}_{2}, \mathrm{H}_{3}$ and $\mathrm{H}_{4}$ were true given the sample data. We note that the posterior odds ratio gives the ratio of the probabilities of the two hypotheses holding given the sample data. On the assumption that all three hypotheses have equal prior probability, then the posterior odds ratio becomes:

$K_{1 j}=\frac{P\left(H_{1} \mid \tilde{y}\right)}{P\left(H_{j} \mid \tilde{y}\right)}, j=2,3,4$.

According to Ahking (1997), the Zelner-Siow posterior odds ratio is approximated by the following: 
$K_{1 j}=\frac{\sqrt{\pi} / \Gamma[(r+1) 0.5](0.5 v)^{0.5 r}}{(1+r F / v)^{(1 / v) / 2}}$

where

$\Gamma[]=$.$\quad the Gamma function, which, in mathematics, is an extended factorial$ function to complex and non-integer numbers;

$T=\quad$ the number of observations;

$v=T-K \quad$ number of observations less the number of linear restrictions;

$k=\quad$ the number of regressors in the null model;

$r=\quad$ the number of linear restrictions to be tested, and

$F=\quad$ the F-statistic for testing the set of linear restrictions.

The following are the particularly relevant values of the gamma function:

$\Gamma[1 / 2] \approx 1.772 ; \Gamma[1]=1 ; \Gamma[1,5] \approx 0.886 ; \Gamma[2]=1 ; \Gamma[5 / 2]=1.329$.

The calculated posterior odds ratios are used to compute the posterior probability for each of the four hypotheses. The results of this analysis, along with the non-linear and linear ADF tests, appear in the next section.

\section{EMPIRICAL EVIDENCE}

SADC dollar-based real exchanges were chosen on the basis of adequate data availability. We used the International Financial Statistics database of the International Monetary Fund. Real exchange rates were derived from the relative form of the purchasing power parity hypothesis, stated in (1), and reported here again for the sake of convenience, as follows:

$y_{t}=\ln Y_{t}=\ln S_{t}-\ln \bar{P}_{t}+\ln P_{t}$,

where $\ln Y_{t}$ is the logarithm of a real exchange rate (domestic price of foreign currency) at time $t ; \ln \bar{P}_{t}$ and $\ln P_{t}$ are the logarithms of foreign and domestic price levels, respectively. The United States consumer price index (CPI) inflation is the all-item CPI inflation and the foreign CPI inflation rates are the general CPI inflation rates of the chosen countries. Sample periods varied according to data availability in respect of CPI inflation and nominal exchange rate series. 


\section{(a) Results from Non-Linear Tests of Non-Stationarity}

In the context of nonlinear analysis, we used partial autocorrelation function to determine the optimal lags. This approach is recommended by Granger and Terasvirta (1993) and Terasvirta (1994). The usage of PACF over that of information criteria represents an effort to avoid possible bias when choosing lag length. The delay parameter was fixed at 1. In general, the appropriate choice of the delay parameter is the one associated with the highest test statistic. However, fixing the delay parameter is generally of little consequence since economic intuition would suggest that smaller values of the delay parameter were to be preferred.

We employed an auxiliary regression appearing in (8) or (49). In this setting, the null and alternative hypotheses are of the form:

$$
\begin{aligned}
& H_{0}: \delta=0, \\
& H_{1}: \delta<0 .
\end{aligned}
$$

Failing to reject the null implies that the real exchange rate should be treated as nonstationary. By contrast, the rejection of the null hypothesis in favour of the alternative implies that the exchange rate is mean-reverting and nonlinear.

KSS provide the simulated asymptotic critical values for the nonlinear unit root tests. For both the nonlinear Dickey-Fuller test and nonlinear ADF tests, the 1, 5 and 10 per cent critical values for the demeaned series are $-3.48,-2.93$ and -2.66 respectively, whereas for the demeaned and detrended series are, in the same order, $-3.93,-3.40$ and -3.13 .

In the context of linear analysis, our dataset has log-levels of real exchange rates and demeaned series. In the case of non-demeaned data, we apply the ADF test. When testing for unit roots, we allow for a constant but no deterministic time trends in the test regression.

The above being said, the pitfalls of the tests should be noted. As was noted by Hall (1994) and Ng and Perron (1995), the ADF tests suffer from low power when the lag length is too small. In some cases, lag selection alone may be responsible for the difference in rejections rates.

Table 1 summarises key inferences that can be made from the above estimation. The results from KSS nonlinear unit root and linear ADF tests are based on the demeaned series and suggest that the null hypothesis of nonstationarity should be rejected at 1 per cent significance level for 4 real exchange rates (Mauritius, South Africa, Swaziland, and Tanzania) out of 10 country exchange rates under study. This suggests that a linear specification for these countries would be inappropriate. In addition, these real exchange rates are mean-reverting but in a nonlinear fashion.

At 1 per cent significance level, all the series were nonstationary. However at 10 per cent significance level the real exchange rates of 6 countries were stationary: Mozambique, 
Madagascar, Mauritius, South Africa, Swaziland, and Tanzania were found to be stationary.

Table $1 \quad$ ADF and Nonlinear ADF test results

\begin{tabular}{|c|c|c|c|c|}
\hline & Sample periods & $\begin{array}{l}\text { Critical values, } \\
\text { ADF }(10 \%)\end{array}$ & Linear ADF & $\begin{array}{l}\text { Nonlinear } \\
\text { ADF }\end{array}$ \\
\hline Angola & 1995M9-2006M6 & -1.62 & -0.55 & -1.98 \\
\hline \multirow{2}{*}{$\begin{array}{l}\text { Botswana } \\
\text { Madagascar } \\
\end{array}$} & 1990M1-2006M6 & & -1.04 & -1.41 \\
\hline & 1990M1-2003M3 & -1.62 & -1.05 & -2.55 \\
\hline Malawi & 1990M12006M6 & -1.62 & -0.39 & -0.50 \\
\hline Mauritius & 1990M1-2006M6 & -1.62 & -3.71 & -6.25 \\
\hline Mozambique & 1993M7-2006M5 & -1.62 & -2.60 & -2.15 \\
\hline South Africa & 1990M1-2006M6 & -1.62 & -2.43 & -6.89 \\
\hline Swaziland & 1990M1-2005M12 & -1.62 & -2.06 & -5.42 \\
\hline Tanzania & 1994M12-2006M6 & -1.62 & -2.26 & -5.95 \\
\hline Zambia & 1990M1-2006M5 & $\begin{array}{c}-1.62 \\
\end{array}$ & -1.09 & -2.08 \\
\hline \multicolumn{5}{|c|}{ NADF Demeaned data significance levels } \\
\hline $10 \%$ & & & & -2.66 \\
\hline $5 \%$ & & & & -2.93 \\
\hline $1 \%$ & & & & -3.48 \\
\hline
\end{tabular}

\section{(b) The Results of Bayesian Unit Root Testing}

According to the results appearing in Table 2, nonstationarity hypothesis receives small posterior probability relative to other hypotheses. In this setting, the Bayesian results strongly support the hypothesis that all the real exchange rates are trend-stationary autoregressive processes.

It is necessary to point out that the Bayesian unit root test results are sharply at odds with the ADF results in that the hypothesis of a unit root does not receive significant posterior probability in all cases. Instead the results seem to support the hypothesis of trendstationarity for all cases. That been said, Ahking (2004) found that that the Bayesian test used in this paper could not distinguish between a trend-stationary autoregressive model from a stationary autoregressive one, especially when the time trend effect was relatively small, and the time series was highly persistent. The latter author found that the bias was in favour of finding a trend-stationary model. Thus, the results should be treated with caution. 


\begin{tabular}{|c|c|c|c|c|c|}
\hline Country & $\operatorname{AR}(p)$ & Trend stationary & Stationary & Unit root & Two trends \\
\hline Angola & 1 & 0.53 & 0.22 & 0.03 & 0.22 \\
\hline Madagascar & 2 & 0.58 & 0.20 & 0.03 & 0.20 \\
\hline Botswana & 1 & 0.62 & 0.18 & 0.02 & 0.18 \\
\hline Malawi & 1 & 0.62 & 0.18 & 0.02 & 0.18 \\
\hline Mauritius & 6 & 0.62 & 0.18 & 0.02 & 0.18 \\
\hline Mozambique & 3 & 0.57 & 0.20 & 0.03 & 0.20 \\
\hline South Africa & 6 & 0.62 & 0.18 & 0.02 & 0.18 \\
\hline Swaziland & 5 & 0.61 & 0.18 & 0.02 & 0.18 \\
\hline Tanzania & 2 & 0.55 & 0.21 & 0.03 & 0.21 \\
\hline Zambia & 1 & 0.62 & 0.18 & 0.02 & 0.18 \\
\hline
\end{tabular}

\section{CONCLUSIONS}

This paper has sought to present evidence indicating that the PPP puzzle is becoming less of a puzzle. It presented the results of ADF test, nonlinear tests of nonstationarity, and Bayesian unit root tests. The Bayesian tests were found to be biased in favour of a trend stationary model in all cases. It is argued that nonlinear approaches to exchange rate adjustments are likely to provide a firmer basis for inference and stronger support for the PPP in the long-term. This is more so at 1 per cent and 5 per cent significance levels.

The results obtained from the KSS tests suggest that the behaviour of 4 dollar-based real exchange rates should be treated as nonlinear rather than linear. This finding of nonlinear behaviour provides statistical evidence in support of a smooth transition meanreverting behaviour in 4 out of 10 real exchange rates. As such, any deviation from the PPP, either over- or under-appreciation of real exchange rates is temporary. 


\section{REFERENCES}

ABUAF, N. and JORION, P. (1990). Purchasing power parity in the long-run. Journal of Finance, 45: 157-74.

BAILLIE, R. T. and KAPETANIOS, G. (2005). Testing for neglected nonlinearity in long memory models. Queen Mary Working Paper number 528, University of London.

BALKE, N. S. and FOMBY, T. (1997). Threshold cointegration. International Economic Review, 38: 627-645.

DAVIES, R. B. (1987). Hypothesis testing when a nuisance parameter is present under the alternative. Biometrika, 74: 33-43.

DEJONG, D. N. and WHITEMAN, C. H. (1991). The case for trend-stationarity is stronger than we thought. Journal of Applied Econometrics, 6: 413-421.

DICKEY, D. A. and FULLER, W. A. (1981). Likelihood ratio statistics for autoregressive time series with a unit root. Econometrica, 49: 1057-1072.

DIEBOLD, F. X and RUDEBUSCH G. D. (1991). On the power of Dickey-Fuller tests against fractional alternatives. Economics Letters, 35: 155-160.

DORNBUSCH, R. (1976). Exchange rate expectations and monetary policy. Journal of International Economics, 6: 231-244.

ELLIOTT, G., ROTHENBERG, T. J. and STOCK, J. H. (1996). Efficient tests for an autoregressive unit root. Econometrica, 64: 813-836.

FRANKEL, J. and ROSE, A. (1995). A Survey of empirical research on nominal exchange Rates, in E. Grossman and K. Rogoff (eds).The Handbook of International Economics. Amsterdam: North Holland.

GRANGER, C. W. J. and TERASVIRTA, T. (1993). Modelling nonlinear economic relationships, Oxford University Press, Oxford.

HALL, A. (1994). Testing for a unit root in time series with pretest data-based model selection. Journal of Business and Economic Statistics, 12: 461-470.

KAPETANIOS, G., SHIN Y. and SNELL A. (2003). Testing for a unit root in the nonlinear STAR framework. Journal of Econometrics, 112:359-379.

KOOP, G. (1992). Objective, Bayesian unit root tests. Journal of Applied Econometrics, 7: 6582.

KOOP, G. (1994). Recent progress in applied Bayesian econometrics. Journal of Economic Survey, 8:1-34.

LEVIN, A. and LIN, C-F. (1992). Unit root tests in panel data: asymptotic and finite sample properties. (Unpublished; Washington: Federal Reserve Board of Governors)

MICHAEL, P., NOBAY, R. A. and PEEL, D. A. (1997). Transactions costs and nonlinear adjustment in real exchange rates: an empirical investigation. Journal of Political Economy, 105:862-879.

MOKOENA, T. M. (2007). Taking the puzzle out of the purchasing power parity puzzle: an application in respect of South Africa. South African Journal of Economics, 75:22-27

MOKOENA, T. M., GUPTA, R. and VAN EYDEN, R. (2008a). Market Microstructure Approach to the Exchange Rate Determination Puzzle. Department of Economics, Working Paper, No. 200810, University of Pretoria.

MOKOENA, T. M., GUPTA, R., and RENEE VAN EYDEN (2008b). Exchange Rate Puzzles: Recent Theoretical and Empirical Developments. Mimeo, Department of Economics, University of Pretoria. 
MOKOENA, T. M., GUPTA, R., and RENEE VAN EYDEN (2008c). Testing for Fractional Integration in SADC Real Exchange Rates. Department of Economics, Working Paper, No. 200811, University of Pretoria.

MOKOENA, T. M., GUPTA, R., and RENEE VAN EYDEN (2008d). Half-Life Deviations from PPP in SADC Countries. Mimeo, Department of Economics, University of Pretoria.

NG, S. and PERRON, P. (2001). Lag length selection and the construction of unit root tests with good size and power. Econometrica, 69:1519-1554.

NORMAN, S. (2006).Testing for a unit root against ESTAR nonlinearity with a delay parameter greater than one. Working Paper, Brigham Young University.

OH, K-Y. (1996). Purchasing power parity and unit root test using panel data. Journal of International Money and Finance, 15:405-418.

PIPPENGER, M. K. and GOERING, G. E. (1993). A note on the empirical power of unit root tests under threshold processes. Oxford Bulletin of Economics and Statistics, 55: 47381.

SARNO, L., TAYLOR, M. and PEEL, D. (2001). Nonlinear mean-reversion in real exchange rates: toward a solution to the purchasing power parity puzzles. International Economic Review, 42:1015-1042.

SARNO, L. and TAYLOR, M P. (2002). Purchasing power parity and the real exchange rate. International Monetary Fund Staff Papers, 49:65-105.

SERCU, P., UPPAL, R. and VAN HULLE, C. (1995). The exchange rate in the presence of transactions costs: implications for tests of purchasing power parity. Journal of Finance, 50: 1309-1319.

SIMS, C. A. (1988). Bayesian skepticism on unit root econometrics. Journal of Economic Dynamics and Control, 12:463-474.

SIMS, C. A. HARALD, U. (1991). Understanding unit rooters: A helicopter tour. Econometrica, 59: 1591-1599.

TAYLOR, A M. (2000). Potential pitfalls for the purchasing-power-parity puzzle? Sampling and specification biases in mean-reversion tests of the law of one price. NBER Working Paper 7577.

TERASVIRTA, T. (1994). Specification, estimation, and evaluation of smooth transition autoregressive models. Journal of the American Statistical Association, 89: 208-218.

WU, Y. (1996). Are real exchange rates nonstationary? evidence from a panel data set. Journal of Money Credit and Banking, 28: 54-63.

ZELLNER, A. and SIOW, A. (1980). Posterior odds for selected regressions hypotheses. In J. M. Bernardo, M. H. De Groot, D. V. Lindley and A. F. M. Smith (eds). Baynesian Statistics. University Press, Valencia. 